\title{
E-SMOKING:
}

\section{EMERGING PUBLIC HEALTH PROBLEM?}

\section{MATEUSZ JANKOWSKI ${ }^{1}$, GRZEGORZ BROŻEK ${ }^{1}$, JOSHUA LAWSON² ${ }^{2}$ SZYMON SKOCZYŃSKI, and JAN EUGENIUSZ ZEJDA ${ }^{1}$}

\author{
${ }^{1}$ Medical University of Silesia in Katowice, Katowice, Poland \\ School of Medicine in Katowice, Department of Epidemiology \\ ${ }^{2}$ University of Saskatchewan, Saskatoon, Canada \\ Canadian Center for Health and Safety in Agriculture, Department of Medicine \\ ${ }^{3}$ Medical University of Silesia in Katowice, Katowice, Poland \\ School of Medicine in Katowice, Department of Pneumonology
}

\begin{abstract}
E-cigarette use has become increasingly popular, especially among the young. Its long-term influence upon health is unknown. Aim of this review has been to present the current state of knowledge about the impact of e-cigarette use on health, with an emphasis on Central and Eastern Europe. During the preparation of this narrative review, the literature on e-cigarettes available within the network PubMed was retrieved and examined. In the final review, 64 research papers were included. We specifically assessed the construction and operation of the e-cigarette as well as the chemical composition of the e-liquid; the impact that vapor arising from the use of e-cigarette explored in experimental models in vitro; and short-term effects of use of e-cigarettes on users' health. Among the substances inhaled by the e-smoker, there are several harmful products, such as: formaldehyde, acetaldehyde, acroleine, propanal, nicotine, acetone, o-methyl-benzaldehyde, carcinogenic nitrosamines. Results from experimental animal studies indicate the negative impact of e-cigarette exposure on test models, such as ascytotoxicity, oxidative stress, inflammation, airway hyper reactivity, airway remodeling, mucin production, apoptosis, and emphysematous changes. The short-term impact of e-cigarettes on human health has been studied mostly in experimental setting. Available evidence shows that the use of e-cigarettes may result in acute lung function responses (e.g., increase in impedance, peripheral airway flow resistance) and induce oxidative stress. Based on the current available evidence, e-cigarette use is associated with harmful biologic responses, although it may be less harmful than traditional cigarettes. Int J Occup Med Environ Health 2017;30(3):329-344
\end{abstract}

Key words:

Smoking, Nicotine, Literature review, E-cigarette, Electronic cigarette, Tobacco products

\section{INTRODUCTION}

The electronic nicotine delivery system called an "electronic cigarette" or "e-cigarette" has become widely popular, especially among young people [1,2]. It has been advertised in the mass media as a safer alternative to traditional cigarettes and as an aid to reduce or quit smoking.
E-cigarettes pose challenges for health policy and public health. It is a new source of nicotine, an addictive substance, which has a proven harmful effect on health [3]. In many countries, e-cigarettes are subject to different laws on tobacco cigarettes $[4,5]$. The sale of e-cigarettes to minors, its use in public places, and its qualification as

Received: June 20, 2016. Accepted: December 4, 2016.

Corresponding author: G. Brożek, Medical University of Silesia in Katowice, School of Medicine in Katowice, Department of Epidemiology, Medyków 18, 40-752 Katowice, Poland (e-mail: gbrozek@sum.edu.pl). 
a medical device or tobacco product should be regulated but these regulations vary by jurisdiction. In addition to this, despite what is portrayed in popular mass media and advertising, the impact of the long-term use of e-cigarettes on health is unknown. While this is true for long-term use, fortunately, there is a growing body of research investigating the short-term impact of e-cigarette use on health as well as evidence from experimental animal studies.

Electronic cigarettes are powered by a battery or accumulator device with a heating element that heats the fluid (the e-liquid) to a temperature of about $200-300^{\circ} \mathrm{C}$ to form an aerosol (vapor) which is inhaled into the lungs. To substitute visual and behavioral aspects of cigarette smoking, e-cigarettes are designed to look like traditional tobacco cigarettes [6]. There are 4 types of e-cigarettes: disposable; first generation-rechargeable cigarette-shaped; second generation pen-style, larger than a cigarette, with a refillable cartridge; third generation tank-style largesized, rechargeable with manual switches, which may be easily modified $[6,7]$.

The aim of this review is to examine the current state of knowledge about the impact of e-cigarette use on health focusing within the context of Eastern and Central Europe, regions with high smoking prevalence. As part of this process, we will:

- review the chemical composition of e-cigarettes and consider the theoretical potential of harm from these devices,

- review evidence from animal studies,

- review evidence from human based short term exposure studies and finally,

- describe the prevalence of e-cigarette use and behavior towards its use as a way of considering the potential burden of a problem.

As such, this review will include an examination of the construction and operation of the e-cigarette, the chemical composition of the e-liquid, the impact of vapor products arising from the use of e-cigarettes on laboratory experimental models in vitro and short-term effects of the use of e-cigarette use on the user's health.

\section{MATERIAL AND METHODS}

To review the evidence, we made use of PubMed for our literature search and included articles published from January 2010 until May 2016. Combinations of following key-words were used: "electronic cigarette," "e-cigarette," "e-cigarettes," "e-cig," "electronic nicotine delivery system" with phrases from the four groups of studies: chemical composition (key words: aerosol, carbonyl compounds, indoor air quality, nicotine, e-liquid, vapor); animal experimental studies (key words: cytotoxicity, lung function, mice, cells); and human based short term exposure studies (key words: safety, health effects, toxicity, secondhand exposure); prevalence of use (key words: smoking, smoking cessation, adolescence, students, e-smoking, reasons for use).

From this search, a total of 1985 potentially relevant articles were identified. This number was reduced to 108 articles after screening titles and abstracts for relevance to the current review by two independent reviewers. The articles dealing partly or exclusively with health effects correlated to e-cigarette exposure were considered as a potentially relevant article. All studies were in English. After reaching a list of potentially relevant articles, the full text of each paper was appraised, with particular emphasis on the time and route of e-cigarette exposure, the characteristics of the population, the presence of a control group and study limitations. Additionally, reference lists from selected publications were searched to identify additional articles that may be relevant to the topic of this review. Case reports, articles that reported health effects caused by direct e-liquid exposure (without combustion), studies involving mental illness among the study group were excluded from further analysis. Although narrative reviews have more potential for bias than meta-analysis, we tried to be systematic and critical in our selection and appraisal of the articles. 
In our review we have attempted to focus on evidence from Central and Eastern Europe. However, we found that there was a limited number of articles from this region. With the exception of Poland, where there were approximately 30 articles, each country had a maximum of 5 articles published. Originally we selected 51 articles. Following suggestions from experts in the field, we selected additional 13 articles resulting in a total of 64 publications, out of which 15 were from Central and Eastern Europe. Experimental studies evaluating exclusively the impact of e-smoking on health are listed in the tables of this review. This was done in order to more extensively present study characteristics and results in order to present the information from each study allowing the reader for a more thorough assessment of the current literature to draw interpretations and final conclusions.

\section{RESULTS}

\section{Chemical composition of the e-liquid and created aerosol}

E-liquids differ in their chemical composition, the content of flavoring substances, and nicotine content (0$24 \mathrm{mg}$ ) [8]. Most of them contain propylene glycol and/ or glycerin, nicotine, water or ethanol, flavors, and other additives [8]. However, there are significant differences between the composition declared on the packaging and the composition resulting from a chemical analysis [8-10]. In particular, differences may occur in the contents of nicotine, where the differences may be greater than 100\% [9]. The European Union (EU) Directive, that has been in force since May 2016, determines the maximum size of the e-liquid containers and limits the concentration of nicotine in e-cigarette liquids to $20 \mathrm{mg} / \mathrm{ml}$ [11]. Currently, there are about 8000 different flavors available for e-cigarettes [12]. Manufacturers offer newer and more diverse flavors like bubblegum, fruit, and chocolate, potentially to encourage young people to reach for the e-cigarette. Some e-smokers, likely due to financial issues and the desire to experiment with something new, are choosing to create homemade e-liquids. Also, there is a risk that the e-cigarette is used as a new tool of inhaling cannabinoids and other psychoactive substances [13].

Among the substances inhaled by an e-smoker, researchers have identified several harmful products including: formaldehyde, acetaldehyde, acroleine, propanal, nicotine, acetone, o-methyl-benzaldehyde, and carcinogenic nitrosamines [10,14,15]. E-cigarette use also results in the emission of particulate matter, which then increases the concentration in ambient air [16,17]. Despite the emission of these substances, emission of these substances was 6-450 times higher in the tobacco cigarette than in the e-cigarette $[14,16]$. There is some evidence suggesting that through the use of new generation e-cigarettes, where the user may adjust the voltage of the device, there is an increased generation of more harmful substances (e.g., formaldehyde) [18]. Jensen et al. examined the concentrations of formaldehyde generated by e-cigarettes featuring a variable-voltage battery [18]. In the case of low levels of e-liquid in the container and at high voltage ( $5 \mathrm{~V})$, heating elements were overheated, resulting in excessive degradation of propylene glycol to formaldehyde [18]. The authors suggest that the e-smoker would be exposed to 5-15 times higher dose of formaldehyde as compared to a traditional smoker [18]. However, these trials were conducted in the laboratory, without human participation, and the voltage applied in the tests may be difficult to reproduce during the daily use of e-cigarettes [18,19].

Passive smoking phenomenon related to e-cigarette use is not the issue as important as it is with smoking tobacco. The vapor exhaled by the user influences only the environment but may contain: volatile organic compounds, 1,2-propanediol, nicotine, and ultrafine/fine particles [20-22]. It is suggested that the concentration of toxic substances to which the passive smoker is exposed, is on average 10 times lower than in the case of tobacco cigarette use $[21,22]$. 


\section{Evidence from experimental animal studies}

In order to identify the effect of e-cigarette exposure experimentally, several in vitro studies on mouse lung cells, human embryonic stem cells, mouse neural stem cells, human pulmonary fibroblasts, and in vivo mouse models have been performed (Table 1). The evidence indicates a negative impact of e-cigarette exposure in these experiments. Experimental studies were performed on mice or in vitro cell models exposed to e-cigarette vaping using a specially constructed "smoking-machine" which provided aerosol exposure [23-30]. However, studies differed in duration, exposure time, and nicotine content in the e-liquid making it difficult to compare the results. Despite this, studies have shown cytotoxic effects of e-cigarette vapor on cells but the level of cytotoxicity was dependent on the flavor of e-liquid [24,26-28]. Coffee and cinnamon flavored e-liquids were the most cytotoxic [24,27,28]. Some sweet flavors such as toffee, butter, milk or chocolate contain diacetyl and acetyl propionyl [31]. In comparison to other flavors, cherry flavored e-liquid is characterized by a higher content of benzaldehyde [32].

Exposure has been shown to induce oxidative stress, inflammatory responses in lung epithelial cells and in the mouse lung, to alter ciliary function and induce cytokine release in lung epithelial cells [23-25]. These changes may play a role in development of disorders occurring with chronic airway inflammation. Some authors have suggested that nicotine delivered by a e-cigarette acts on the nicotinic receptor and causes the influx of calcium into the cell which increases protein kinase C-alpha (PKC- $\alpha$ ) and extracellular signal-regulated kinase (ERK) and activates a cascade of reactions [23] responsible for: inducting airway hyper reactivity, airway remodeling, mucin production and apoptosis, emphysematous changes, and increased airway resistance in response to methacholine [25]. These experiments help identify and understand the processes that occur in cells during the use of e-cigarettes. However, some authors who had investigated the impact of e-cigarette and cigarette smoking on mouse lungs, concluded that the effect of e-cigarette smoking was significantly lower as compared to the effect of cigarette smoking [29]. Results from one study carried out on cell lines of human tracheobronchial epithelium suggested that there were no significant changes in cell viability after e-cigarette exposure and the results were similar to the control group exposed to air [30]. Future research should be extended to further investigate the effects of e-smoking as a possible risk factor for the development of chronic respiratory diseases.

\section{Short-term impact of e-cigarette use on health}

Due to the fact that e-cigarettes have only been in the market for a decade, studies on the long term effects of e-smoking on health are not available. However, the short-term impact of e-cigarette use on health has been described in the literature (Table 2). The findings indicate that the use of e-cigarettes may result in short-term responses. Questionnaire-based assessment indicates that the use of e-cigarettes is responsible for mouth and throat irritation, dry cough [33], headache, nausea, dyspnea, and vertigo [1].

In experimental studies of smokers where e-smokers and control subjects were included, the acute effects of using an e-cigarette were compared. However, research protocols differed in terms of time of using the e-cigarette, amount of puffs taken, and nicotine content in the e-liquid. In the future, consistency between studies would allow for a more accurate comparison and interpretation of results. An experimental study assessing the effect of short-term e-cigarette vapor exposure on normal epithelial cells and head and neck squamous cell carcinoma (HNSCC) cell lines revealed a reduction in cell viability and clonogenic survival as compared to untreated controls [34]. Even after one week, researchers noticed an induction of deoxyribonucleic acid (DNA) breakage and cell death. These findings suggest genotoxic and carcinogenic effects of e-cigarette use [34]. 

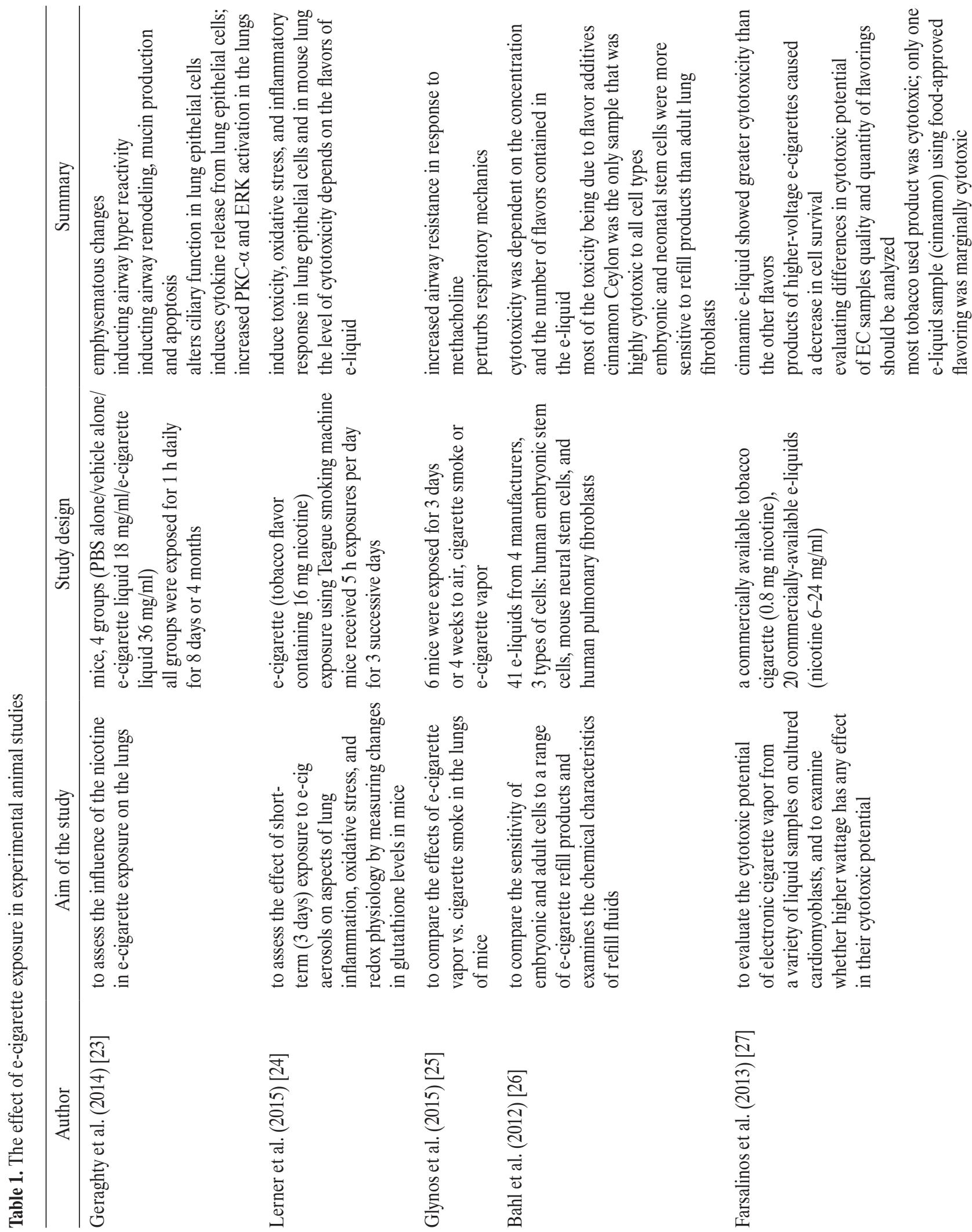


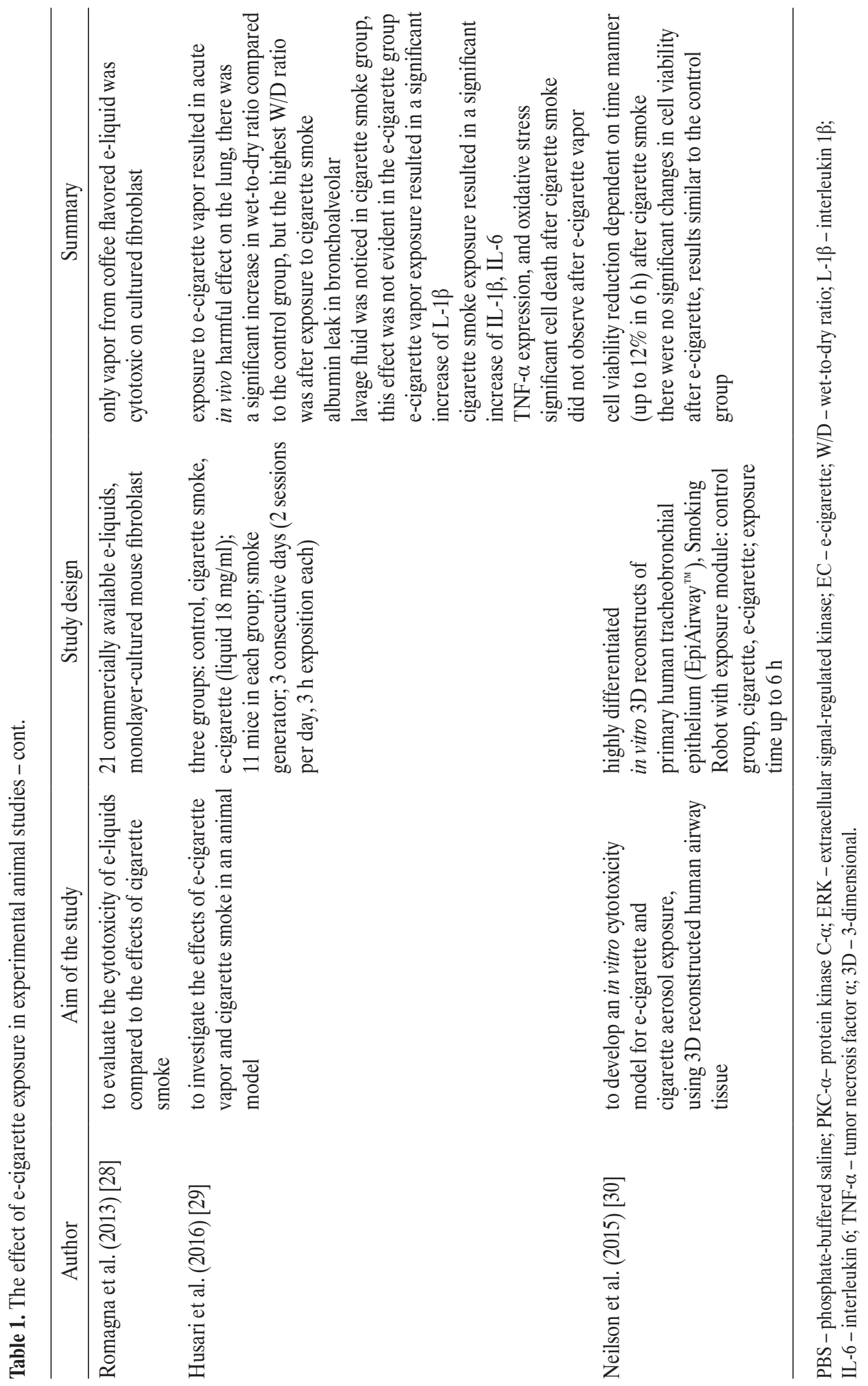




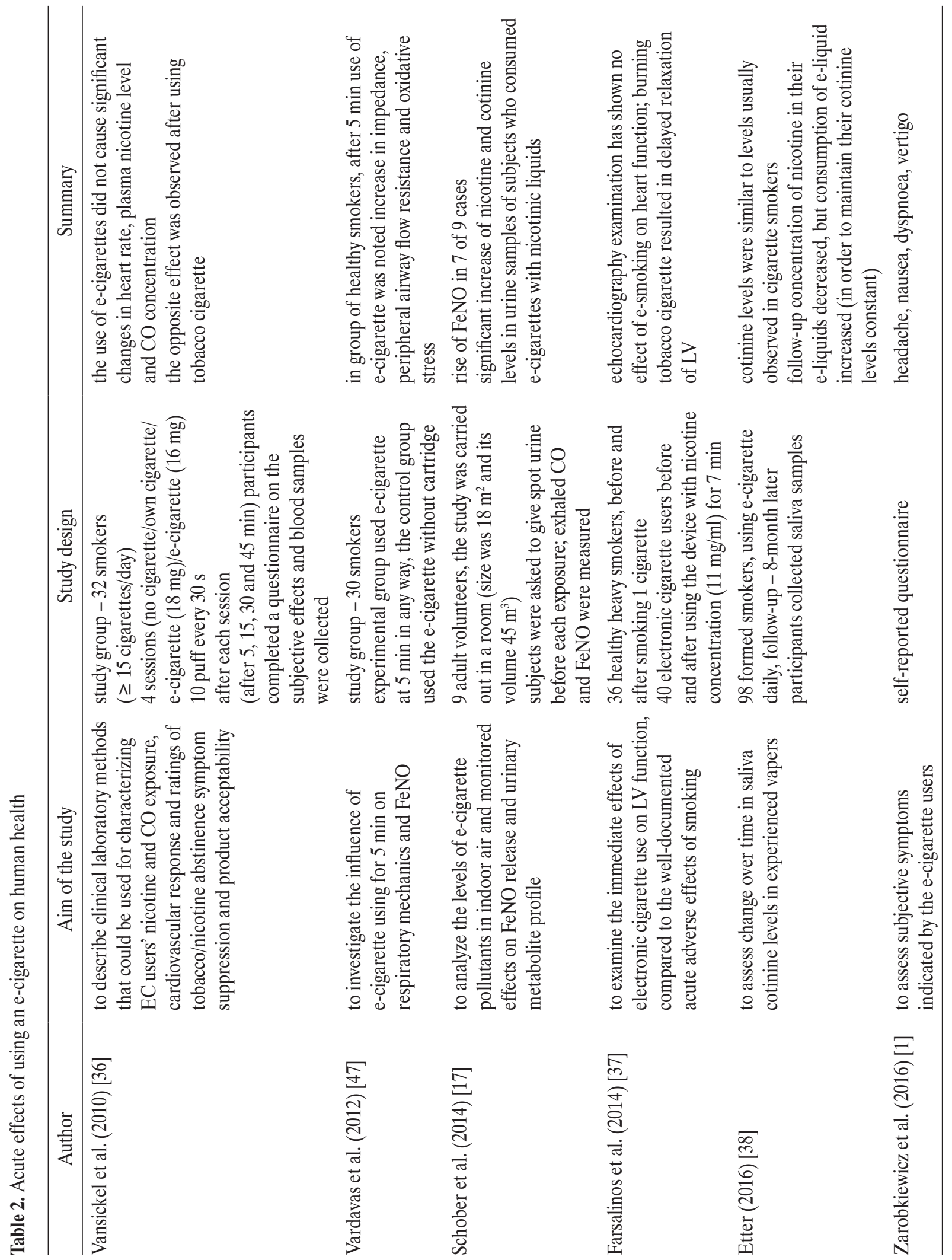




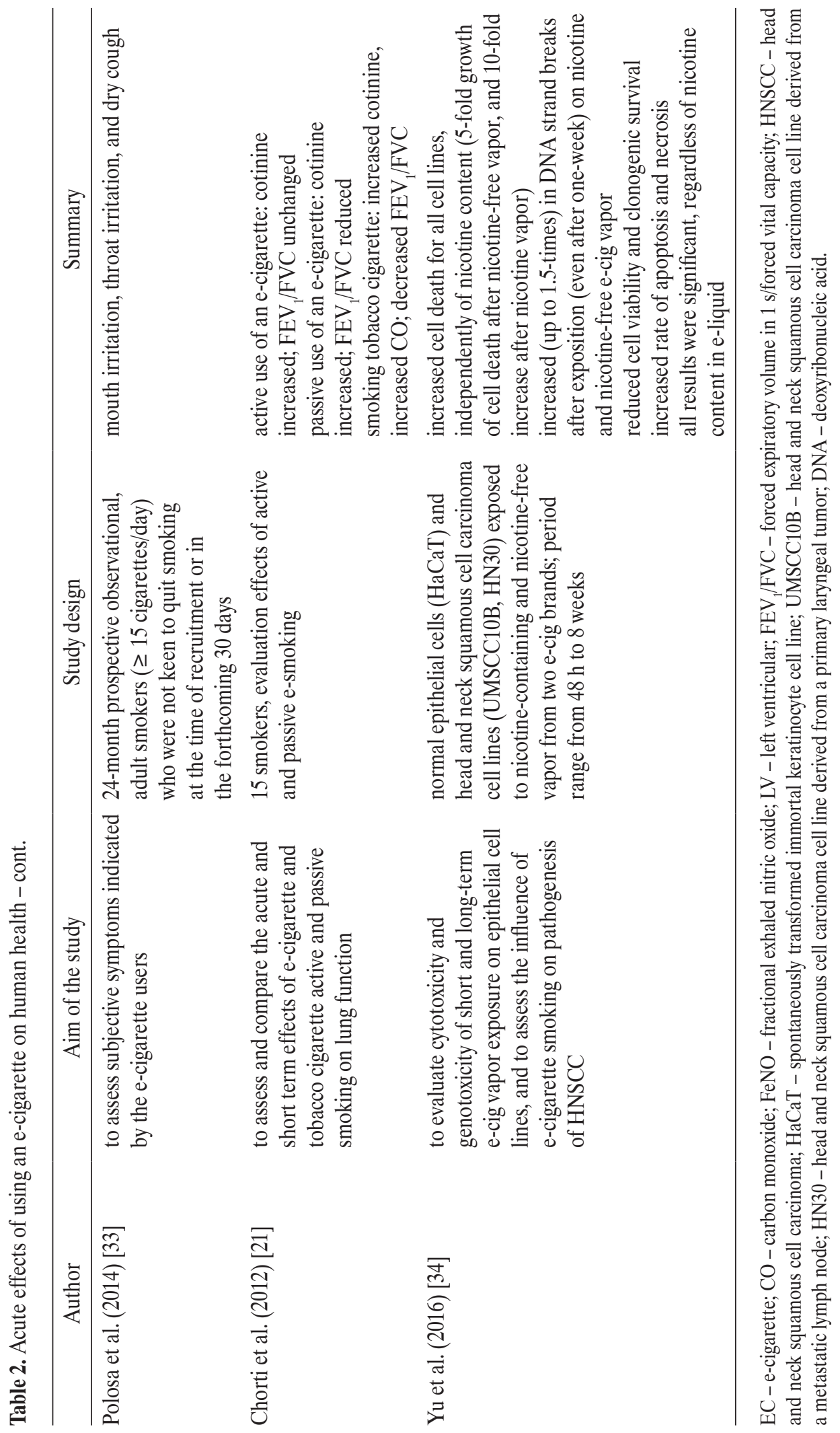


Active and passive e-cigarette usage were not found to increase white blood cell count, lymphocyte count, and granulocyte count [35]. For comparison purposes, in the tobacco cigarette smoking group there was an increase in the count of all 3 components of blood cell counts [35]. The use of e-cigarettes has not been shown to cause significant changes in heart rate, plasma nicotine levels, or carbon monoxide (CO) concentration [17,36]. The opposite effects were observed among tobacco cigarettes smokers [17,36]. Echocardiography showed no effect of e-smoking on heart function while smoking a tobacco cigarette resulted in delayed relaxation of left ventricu$\operatorname{lar}(\mathrm{LV})$ [37]. E-cigarette usage caused significant increase in biological levels of nicotine and cotinine [17,38-40]. In some cases, the results were similar to levels typically observed among cigarette smokers. Etter [38] investigated the level of saliva cotinine in daily e-cigarette smokers. Their evidence suggests that mean cotinine levels are similar (281-310 ng/ml [38], 322 ng/ml [39], 373 ng/ml [40]) to levels previously observed among traditional cigarette smokers (245 ng/ml [41], $300 \mathrm{ng} / \mathrm{ml}$ [42], $338 \mathrm{ng} / \mathrm{ml}$ [43]). Schober et al. observed a significant increase in cotinine and nicotine levels in urine samples of e-cigarette smokers who used nicotinic e-liquids [17]. Mean cotinine in urine of active smokers and active users of e-cigarettes were found comparable [44]. Passive smoking and passive vaping led to comparable cotinine levels in serum of bystanders $[45,46]$.

Short-term, acute respiratory responses were found among healthy smokers [17,21,47]. After 5 min of use of an e-cigarette, lung impedance, peripheral airway flow resistance, and oxidative stress increased [47]. Another study also showed that after e-smoking, fractional exhaled nitric oxide (FeNO) level increased for 7 out of 9 cases [17]. In one study, passive e-cigarette use was associated with reduction in forced expiratory volume for $1 \mathrm{~s} /$ forced vital capacity $\left(\mathrm{FEV}_{1} / \mathrm{FVC}\right)$ while during active e-cigarette use, there were no changes in $\mathrm{FEV}_{1} / \mathrm{FVC}$ [21]. In some cases, the effect observed after using an e-cigarette is smaller as compared to the use of tobacco cigarettes. However, the findings prove poor repeatability between the studies. The main limitations of the published evidence include small sample sizes, inconsistent content of nicotine in the e-liquid, and focus on the short-term impact of e-cigarette use on health. The letter point is the prelude to the discussion on long-term effect of e-cigarette smoking on human health. This topic needs further investigation.

\section{The frequency of the use of e-cigarettes in the population, attitudes, motivations}

E-cigarettes are advertised in the mass media as a safer alternative to traditional cigarettes which, thanks to the absence of combustion, is less toxic than tobacco cigarette exposure. E-cigarette use has become increasingly popular, especially among the young $[2,48]$. The unknown longterm impacts of e-cigarette use justify the view that regulations should be imposed on the sale of e-cigarettes, which should be monitored, prohibited for minors, and advertising should be limited until the evidence related to health is more clear [2,49-51].

Data from the 2012 Eurobarometer 385 survey [48], which included a population of 26566 young adult smokers from 27 countries, indicated that $20.3 \%$ had ever used an e-cigarette overall. Young people from Central and Eastern Europe declared that they used e-cigarettes more often in comparison to the EU average. Estimates differ between countries: $34.3 \%$ in Czech Republic, $31.1 \%$ in Bulgaria, 31.0\% in Poland, 22.3\% in Hungary, 22.3\% in Estonia, 22.2\% in Romania, $8.8 \%$ in Italy, $10.9 \%$ in Spain, $11.5 \%$ in Belgium, $12.4 \%$ in Sweden, and $13.7 \%$ in Austria [48]. E-cigarette use was most popular in Denmark (36.3\%) and the least popular in Slovakia (7.9\%) [48]. National surveys show that $31.5 \%$ of Polish university students had ever used an e-cigarette [1]. Current use of e-cigarettes was declared by $8.3 \%$ of students, with a significant difference between students of non-medical universities 
and medical universities (12.4\% and 4.4\%, respectively) [1]. Among adolescents (15-19 years) there was an increase in the frequency of e-cigarette use [2]. Comparing the data from the years 2013-2014 to the data from 2010-2012, $62.1 \%$ (in 2013-2014) vs. 16.8\% (in 2010-2012) had ever used e-cigarettes [2,52]. The percentage share of current users of e-cigarettes increased from 5.5\% to $29.9 \%$ [2,52]. The use of both types of a cigarette (dual-users) increased from $3.6 \%$ to $21.8 \%$ [2,52]. In the same study, the current use of cigarettes was declared to be $38.0 \%$ [2].

Based on the data obtained from adolescents in Poland, Goniewicz et al. suggest that the e-cigarette does not displace a tobacco cigarette because not only is the e-cigarette prevalence growing but also the frequency of use of e-cigarettes is higher [2]. Dual users compared to exclusive e-cigarette users use both types of cigarettes more often and are exposed to higher nicotine dose, which may suggest a greater nicotine addiction in this group [2,53]. Most dual users initially smoked tobacco cigarettes and then opted for the e-cigarette [53]. However, in a group of dual users, $15.7 \%$ declared that e-cigarettes were the first product they had tried [53]. During an 8-month observation of long-term daily users of e-cigarettes, the concentration of nicotine in their e-liquids decreased but consumption of e-liquid increased which led to maintaining their cotinine levels indicating the strength of nicotine dependence.

Data from the Czech Republic obtained for a group of 1738 adult smokers indicates that $50 \%$ has ever used an e-cigarette [54]. Current use of e-cigarettes was declared by $9.5 \%$ of responders. As a reason for using e-cigarettes, $39.5 \%$ of e-smokers indicated a desire to reduce the use of tobacco cigarettes while $28 \%$ had decided to use e-cigarettes because they may use it in places where conventional cigarettes are prohibited. In a group of persons who have ever used e-cigarettes, $38 \%$ were disappointed after the first experience with an e-cigarette [54].

The study conducted on a sample of 826 undergraduate students at two Hungarian universities showed that $24.9 \%$ of students (24,3\% medical and $25.3 \%$ non-medical) had ever used an e-cigarette [55]. Moreover, $11 \%$ of students who had never tried e-cigarettes had declared their willingness to try e-cigarettes in the near future. In this study, fewer than $1 \%$ of students reported current use of e-cigarette [55].

In many studies involving students, the most common reasons to choose the e-cigarette were: hanging-out with friends, partying, before going to the bed, and stressful moments [1]. Motivation to start e-smoking was to quit or reduce smoking tobacco, the possibility to use in public places, health considerations, and financial concerns [1,54-57]. The survey performed for a group of Parisian school children (12-19 years old) revealed that nearly $10 \%$ of e-cigarette experimenters were not traditional cigarette smokers [58]. The predictors of e-cigarette experimentation from this study included older age, smoking of a friend or brother, current cigarette or shisha smoking, and, somewhat paradoxically, the prohibition to smoke by parents [58]. Results from a study performed in the United States (US) among working adults showed that $3.8 \%$ of this group were current e-cigarette users [59]. The highest prevalence of e-smoking (5.1\%) was among young adults (18-24 years old) [59]. Workers in the accommodation and food services industry had the highest prevalence of e-cigarette use $(6.9 \%)$ in contrast to workers in education services with the lowest e-cigarette use prevalence $(1.8 \%)$ [59].

One of the main reasons for deciding to use e-cigarettes is an attempt to reduce amount of smoking traditional cigarettes and some studies discuss that aspect $[49,60]$. In one trial, middle-aged, high dependent smokers who were motivated to quit smoking were divided into 3 groups: 289 were using nicotine (16 mg) e-cigarettes; 73 people used e-cigarettes without nicotine; 295 investigated used $21 \mathrm{mg}$ nicotine replacement therapy (NRT) patches [60]. All the participants were supported by behavioral therapy. After 6 months, the abstinence of tobacco cigarettes 
was measured using a self-reported questionnaire and confirmed by measuring exhaled carbon monoxide. In the group of e-cigarette users, $7.3 \%$ stopped smoking as compared to $5.8 \%$ of NRT users and the difference was not statistically significant [60]. In another trial, middleaged, high dependent smokers who were not motivated to quit smoking were divided into 3 groups and completed the intervention over 12 weeks [61]. Groups differed in exposure time and nicotine content in the e-liquid [61].

Follow-up was performed after 52 weeks. The highest smoking cessation rate $(13 \%)$ was obtained for the group which used e-cigarette with the highest nicotine content [61]. All e-cigarette users had lower smoking cessation rates $(13 \%, 9 \%, 4 \%$, respectively, as compared to placebo (9-15.6\%) in leading research on the effectiveness of NRT, bupropinon and varenicline in smoking cessation [62,63]. Based on it, there is not enough conclusive evidence proving that e-cigarettes constitute effective method of aiding smoking cessation.

\section{Position of leading health organizations on e-cigarettes}

According to the World Health Organization, there is not enough evidence that smoking e-cigarettes is an effective method of aiding smoking cessation [49]. With the objective of combating nicotine dependence, it is recommended to use tested and approved nicotine replacement therapy [49]. In the absence of conclusive evidence of safety and the health impact of the use of the e-cigarette, it is recommended that there should be restrictions on advertising of e-cigarettes, especially e-liquids of fruit and sweet flavors which are particularly likely to encourage young people to start using the e-cigarette. The World Health Organization also indicates that it is necessary to prohibit the sale of e-cigarettes to minors [49].

A similar position has been agreed upon as the Forum of International Respiratory Societies (FIRS), which indicates that until clear data on the safety and health impact of e-smoking is available, e-cigarettes should be restricted or banned [50]. The Forum of International Respiratory Societies also warns that the growing popularity of e-cigarettes may increase the social acceptance of smoking and nicotine addiction, which is a significant public health problem [50]. The American Heart Association and European Respiratory Society points out that the market of e-cigarettes should be closely monitored, and based on scientific evidence there should be a decision to regulate and determine the legal status of the e-cigarette [50,51]. Similar conclusions were reported by Neuberger who warned against e-cigarettes in the initial Central European review on this subject, where the author was comparing e-cigarettes to a "wolf in sheep's clothing" [64].

The European Union in the Tobacco Products Directive (2014/40/EU) indicates that e-smoking is a major public health problem because e-cigarettes simulate smoking behavior and social approval for smoking [11]. It notes that it may lead to experimentation with other products containing nicotine. The EU also notes that there is no evidence of the influence of long term e-cigarette use on public health. The EU Directive sets rules on packaging and labeling. Its purpose is to have the actual chemical composition declared and be consistent with the true value and reduce nicotine content in the e-liquid to $20 \mathrm{mg} / \mathrm{ml}$, which will be adequate for the majority of vapers [11]. The directive came into force in the Member States on 20 May 2016.

\section{CONCLUSIONS}

Smoking e-cigarettes is becoming an increasingly popular habit and in some populations the frequency of their use is growing steadily. The prevalence of e-cigarette use is higher among the youth from Central and Eastern Europe compared to other countries in Europe. The analysis of chemical composition of e-cigarette vapor indicates the presence of toxic and harmful substances, such as: formaldehyde, acetaldehyde, acroleine, propanal, nicotine, acetone, o-methyl-benzaldehyde, carcinogenic 
nitrosamines, fine and ultrafine particulate matter. Exposure to these substances depends on the type of e-liquid flavor as well as heating conditions and may lead to various respiratory disorders including symptoms of cough and shortness of breath, irritation of upper respiratory airways, lung function impairment, and even diseases such as bronchiolitis.

Results from animal experiments indicate the negative impact of e-cigarette exposure on biological processes including cytotoxicity, oxidative stress, inflammation, airway hyper reactivity, airway remodeling, mucin production, apoptosis, and emphysematous changes. Findings provided by human studies show the short-term impact of e-smoking on health and the convincing data points to such disorders as changes in lung function (e.g., increase in lung impedance, peripheral airway flow resistance) and involvement of the mechanism of oxidative stress. Although the current state of knowledge supports the view that e-smoking poses smaller health risk as compared to tobacco smoking, it is too early to conclude that smokers have an access to a safer substitute of tobacco use. Both habits, tobacco smoking and e-smoking are associated with apparent health risks even if the latter seems to be smaller in terms of the available evidence. Against this argument it is obvious that some preventive measures have been already discussed and apart from research needs there is a move towards regulations regarding advertising and the sale of e-cigarette to minors. On the other hand, e-cigarettes may be considered or even recommended as a safer alternative to tobacco smoking, which is why there is a need to promote proven smoking cessation measures, including pharmacological therapies.

Accumulated evidence regarding the impact of e-smoking on human health shows several gaps and this is understandable, given a short history of the habit. Future studies will provide more information about the relationship between short-term and long-term consequences of e-smoking, particularly from the epidemiological point of view.
Nevertheless toxicological characterization of personal exposures generated by e-smoking and already available findings from animal and human studies justify the view that e-smoking is an emerging public health priority and as such requires more actions in terms of research and health promotion, both leading to sound public health recommendations.

\section{REFERENCES}

1. Zarobkiewicz MK, Wawryk-Gawda E, Woźniakowski MM, Sławiński MA, Jodłowska-Jędrych B. Tobacco smokers and electronic cigarettes users among Polish universities students. Rocz Panstw Zakl Hig. 2016;67(1):75-80.

2. Goniewicz ML, Gawron M, Nadolska J, Balwicki L, Sobczak A. Rise in electronic cigarette use among adolescents in Poland. J Adolesc Health. 2014;55(5):713-5, https://doi. org/10.1016/j.jadohealth.2014.07.015.

3. Heishman SJ, Kleykamp BA, Singleton EG. Meta-analysis of the acute effects of nicotine and smoking on human performance. Psychopharmacology. 2010;210(4):453-69, https://doi. org/10.1007/s00213-010-1848-1.

4. Dawkins L, Turner J, Roberts A, Soar K. 'Vaping' profiles and preferences: An online survey of electronic cigarette users. Addiction. 2013;108(6):1115-25, https://doi.org/10.1111/ add. 12150.

5. Cressey D. Regulation stacks up for e-cigarettes. Nature. 2013;501(7468):473, https://doi.org/10.1038/501473a.

6. Caponnetto P, Campagna D, Papale G, Russo C, Polosa R. The emerging phenomenon of electronic cigarettes. Expert Rev Respir Med. 2012;6(1):63-74, https://doi.org/10.1586/ ers.11.92.

7. Farsalinos KE, Spyrou A, Tsimopoulou K, Stefopoulos C, Romagna G, Voudris V. Nicotine absorption from electronic cigarette use: Comparison between first and new-generation devices. Sci Rep. 2014;4:4133, https://doi.org/10.1038/srep04133.

8. Goniewicz ML, Kuma T, Gawron M, Knysak J, Kosmider L. Nicotine levels in electronic cigarettes. Nicotine Tob Res. 2013;15(1):158-66, https://doi.org/10.1093/ntr/nts103. 
9. Cheng T. Chemical evaluation of electronic cigarettes. Tob Control. 2014;23:ii11-7, https://doi.org/10.1136/tobaccocontrol-2013-051482.

10. Westenberger BJ. Evaluation of e-cigarettes [Internet]. St. Louis: Food and Drug Administration; 2009 [cited 2016 May 11]. Available from: http://www.fda.gov/downloads/ drugs/Scienceresearch/UCM173250.pdf.

11. Directive 2014/40/EU of the European Parliament and of the Council of 3 April 2014 [Internet]. Luksemburg: EURLex [cited 2016 May 11]. Available from: http://eur-lex.europa.eu/legal-content/EN/TXT/?uri = celex:32014L0040.

12. Zhu SH, Sun JY, Bonnevie E, Cummins SE, Gamst A, Yin L, et al. Four hundred and sixty brands of e-cigarettes and counting: Implications for product regulation. Tob Control. 2014;23(3):iii3-9, https://doi.org/10.1136/tobaccocontrol-2014-051670.

13. Giroud C, de Cesare M, Berthet A, Varlet V, Concha-Lozano N, Favrat B. E-cigarettes: A review of new trends in cannabis use. Int J Environ Res Public Health. 2015;12(8):998810008, https://doi.org/10.3390/ijerph120809988.

14. Goniewicz ML, Knysak J, Gawron M, Kośmider L, Sobczak A, Kurek J, et al. Levels of selected carcinogens and toxicants in vapour from electronics cigarettes. Tob Control. 2014;23(2):133-9, https://doi.org/10.1136/tobaccocontrol-2012-050859.

15. McAuley TR, Hopke PK, Zhao J, Babaian S. Comparison of the effects of e-cigarette vapor and cigarette smoke on indoor air quality. Inhal Toxicol. 2012;24:850-7, https:/doi. org/10.3109/08958378.2012.724728.

16. Pellegrino RM, Tinghino B, Mangiaracina G, Marani A, Vitali M, Protano C, et al. Electronic cigarettes: An evaluation of exposure to chemicals and fine particulate matter (PM). Ann Ig. 2012;24:279-88.

17. Schober W, Szendrei K, Matzen W, Osiander-Fuchs H, Heitmann D, Schettgen T, et al. Use of electronic cigarettes (e-cigarettes) impairs indoor air quality and increases FeNO levels of e-cigarette consumers. Int J Hyg Environ Health. 2014;217(6):628-37, https://doi.org/10.1016/j.ijheh.2013.11.003.
18. Jensen RP, Luo W, Pankow JF, Strongin RM, Peyton DH. Hidden formaldehyde in e-cigarette aerosols. N Engl J Med. 2015;372(4):392-4, https://doi.org/10.1056/NEJMc1413069.

19. Kosmider L, Sobczak A, Fik M, Knysak J, Zaciera M, Kurek J, et al. Carbonyl compounds in electronic cigarette vapors: Effects of nicotine solvent and battery output voltage. Nicotine Tob Res. 2014;16(10):1319-26, https://doi.org/ 10.1093/ntr/ntu078.

20. Schripp T, Markewitz D, Uhde E, Salthammer T. Does e-cigarette consumption cause passive vaping? Indoor Air. 2013;23:25-31, https://doi.org/10.1111/j.1600-0668.2012. 00792.x.

21. Chorti M, Poulianti K, Jamurtas A, Kostikas K, Tzatzarakis M, Vynias D, et al. Effects of active and passive electronic and tobacco cigarette smoking on lung function. Abstracts. Toxicol Lett. 2012;21(1S):64, https://doi.org/10.1016/ j.toxlet.2012.03.250.

22. Czogala J, Goniewicz ML, Fidelus B, Zielinska-Danch W, Travers MJ, Sobczak A. Secondhand exposure to vapors from electronic cigarettes. Nicotine Tob Res. 2014;16(6):655-62, https://doi.org/10.1093/ntr/ntt203.

23. Geraghty P, Dabo J, Garcia-Arcos I, Cummins N, Foronjy R. Late-breaking abstract: E-cigarette exposure induces pathological responses that result in lung tissue destruction and airway hyper reactivity in mice. Eur Respir J [Internet]. 2014 [cited 2016 May 16];44(58):3435. Available from: http://erj. ersjournals.com/content/44/Suppl_58/3435.

24. Lerner CA, Sundar IK, Yao H, Gerloff J, Ossip DJ, McIntosh S, et al. Vapors produced by electronic cigarettes and e-juices with flavorings induce toxicity, oxidative stress, and inflammatory response in lung epithelial cells and in mouse lung. PLoS One. 2015;10(2):e0116732, https://doi. org/10.1371/journal.pone.0116732.

25. Glynos C, Bibli S, Pavlidou A, Katsaounou P, Kalomenidis I, Zakynthinos S, et al. Comparison of the effects of e-cigarette vapor vs cigarette smoke on lung function and inflammation in mice. Eur Respir J. 2015;46(59):OA279, https://doi. org/10.1183/13993003.congress-2015.OA279. 
26. Bahl V, Lin S, Xu N, Davis B, Wang YH, Talbot P. Comparison of electronic cigarette refill fluid cytotoxicity using embryonic and adult models. Reprod Toxicol. 2012;34(4):52937, https://doi.org/10.1016/j.reprotox.2012.08.001.

27. Farsalinos KE, Romagna G, Allifranchini E, Ripamonti E, Bocchietto E, Todeschi S, et al. Comparison of the cytotoxic potential of cigarette smoke and electronic cigarette vapour extract on cultured myocardial cells. Int J Environ Res Public Health. 2013;10(10):5146-62, https://doi.org/10.3390/ij erph10105146.

28. Romagna G, Allifranchini E, Bocchietto E, Todeschi S, Esposito M, Farsalinos KE. Cytotoxicity evaluation of electronic cigarette vapor extract on cultured mammalian fibroblasts (ClearStream-LIFE): Comparison with tobacco cigarette smoke extract. Inhal Toxicol. 2013;25(6):354-61, https://doi. org/10.3109/08958378.2013.793439.

29. Husari A, Shihadeh A, Talih S, Hashem Y, El Sabban M, Zaatari G. Acute exposure to electronic and combustible cigarette aerosols: Effects in an animal model and in human alveolar cells. Nicotine Tob Res. 2016;18(5):613-9, https:// doi.org/10.1093/ntr/ntv169.

30. Neilson L, Mankus C, Thorne D, Jackson G, DeBay J, Meredith $\mathrm{C}$. Development of an in vitro cytotoxicity model for aerosol exposure using 3D reconstructed human airway tissue; application for assessment of e-cigarette aerosol. Toxicol In Vitro. 2015;29(7):1952-6, https://doi.org/10.1016/j.tiv. 2015.05.018.

31. Farsalinos KE, Kistler KA, Gillman G, Voudris V. Evaluation of electronic cigarette liquids and aerosol for the presence of selected inhalation toxins. Nicotine Tob Res. 2015;17(2):168-74, https://doi.org/10.1093/ntr/ntu176.

32. Kosmider L, Sobczak A, Prokopowicz A, Kurek J, Zaciera M, Knysak J, et al. Cherry-flavoured electronic cigarettes expose users to the inhalation irritant, benzaldehyde. Thorax. 2016;71(4):376-7, https://doi.org/10.1136/thoraxjnl-2015-207895.

33. Polosa R, Morjaria JB, Caponnetto P, Campagna D, Russo C, Alamo A, et al. Effectiveness and tolerability of electronic cigarette in real-life: A 24-month prospective observational study. Intern Emerg Med. 2014;9(5):537-46, https://doi.org/10.1007/s11739-013-0977-z.

34. Yu V, Rahimy M, Korrapati A, Xuan Y, Zou AE, Krishnan $\mathrm{AR}$, et al. Electronic cigarettes induce DNA strand breaks and cell death independently of nicotine in cell lines. Oral Oncol. 2016;52:58-65, https://doi.org/10.1016/ j.oraloncology.2015.10.018.

35. Flouris AD, Poulianiti KP, Chorti MS, Jamurtas AZ, Kouretas D, Owolabi EO, et al. Acute effects of electronic and tobacco cigarette smoking on complete blood count. Food Chem Toxicol. 2012;50:3600-3, https://doi.org/10.1016/j.fct. 2012.07.025.

36. Vansickel AR, Cobb CO, Weaver MF. A clinical laboratory model for evaluating the acute effects of electronic cigarettes: Nicotine delivery profile and cardiovascular and subjective effects. Cancer Epidemiol Biomarkers Prev. 2010;19:1945-53, https://doi.org/10.1158/1055-9965.EPI-10-0288.

37. Farsalinos KE, Tsiapras D, Kyrzopoulos S, Savvopoulou M, Voudris V. Acute effects of using an electronic nicotine-delivery device (electronic cigarette) on myocardial function: Comparison with the effects of regular cigarettes. BMC Cardiovasc Disord. 2014;14:78, https://doi.org/10.1186/14712261-14-78.

38. Etter JF. A longitudinal study of cotinine in long-term daily users of e-cigarettes. Drug Alcohol Depend. 2016;160: 218-21, https://doi.org/10.1016/j.drugalcdep.2016.01.003.

39. Etter JF, Bullen C. Saliva cotinine levels in users of electronic cigarettes. Eur Respir J. 2011;38(5):1219-20, https://doi. org $/ 10.1183 / 09031936.00066011$.

40. Etter JF. Levels of saliva cotinine in electronic cigarette users. Addiction. 2014;109(5):825-9, https://doi.org/10.1111/ add.12475.

41. Gourlay SG, Benowitz NL, Forbes A, McNeil JJ. Determinants of plasma concentrations of nicotine and cotinine during cigarette smoking and transdermal nicotine treatment. Eur J Clin Pharmacol. 1997;51(5):407-14, https://doi. org/10.1007/s002280050222. 
42. Benowitz NL, Zevin S, Jacob P 3rd. Sources of variability in nicotine and cotinine levels with use of nicotine nasal spray, transdermal nicotine, and cigarette smoking. Br J Clin Pharmacol. 1997;43(3):259-67, https://doi.org/10.1111/j.13 65-2125.1997.00566.x.

43. Gariti P, Alterman AI, Barber W, Bedi N, Luck G, Cnaan A. Cotinine replacement levels for a $21 \mathrm{mg} /$ day transdermal nicotine patch in an outpatient treatment setting. Drug Alcohol Depend. 1999;54(2):111-6, https://doi.org/10.1016/ S0376-8716(98)00163-X.

44. Goney G, Cok İ, Tamer U, Burgaz S, Şengezer T. Urinary cotinine levels of electronic cigarette (e-cigarette) users. Toxicol Mech Methods. 2016;26(6):414-8, https://doi.org/10. 3109/15376516.2016.1144127.

45. Flouris AD, Chorti MS, Poulianiti KP, Jamurtas AZ, Kostikas K, Tzatzarakis MN, et al. Acute impact of active and passive electronic cigarette smoking on serum cotinine and lung function. Inhal Toxicol. 2013;25(2):91-101, https://doi. org/10.3109/08958378.2012.758197.

46. Ballbè M, Martínez-Sánchez JM, Sureda X, Fu M, PérezOrtuño R, Pascual JA, et al. Cigarettes vs. e-cigarettes: Passive exposure at home measured by means of airborne marker and biomarkers. Environ Res. 2014;135:76-80, https://doi. org/10.1016/j.envres.2014.09.005.

47. Vardavas CI, Anagnostopoulos N, Kougias M, Evangelopoulou V, Connolly GN, Behrakis PK. Short-term pulmonary effects of using an electronic cigarette. Chest. 2012;141: 1400-6, https://doi.org/10.1378/chest.11-2443.

48. Vardavas CI, Filippidis FT, Agaku IT. Determinants and prevalence of e-cigarette use throughout the European Union: A secondary analysis of 26566 youth and adults from 27 countries. Tob Control. 2015;24(5):442-8, https://doi. org/10.1136/tobaccocontrol-2013-051394.

49. World Health Organization Framework Convention on Tobacco Control. Conference of the Parties to the WHO Framework Convention on Tobacco Control, sixth session; 2013 Oct 13-18; Moscow, Russian Federation. The Convention; 2014.
50. Schraufnagel DE, Blasi F, Drummond MB, Lam DC, Latif E, Rosen MJ, et al. Forum of International Respiratory Societies; Electronic cigarettes. A position statement of the forum of international respiratory societies. Am J Respir Crit Care Med. 2014;190(6):611-8, https://doi.org/10.1164/ rccm.201407-1198PP.

51. Bhatnagar A, Whitsel LP, Ribisl KM, Bullen C, Chaloupka F, Piano MR, et al. Electronic cigarettes: A policy statement from the American Heart Association. Circulation. 2014;130:1418-36, https://doi.org/10.1161/CIR.0000000000 000107.

52. Goniewicz ML, Zielinska-Danch W. Electronic cigarette use among teenagers and young adults in Poland. Pediatrics. 2012;130(4):e879-85, https://doi.org/10.1542/peds.20 11-3448.

53. Goniewicz ML, Leigh NJ, Gawron M, Nadolska J, Balwicki $\mathrm{L}$, McGuire $\mathrm{C}$, et al. Dual use of electronic and tobacco cigarettes among adolescents: A cross-sectional study in Poland. Int J Public Health. 2016;61(2):189-97, https://doi. org/10.1007/s00038-015-0756-X.

54. Kralikova E, Novak J, West O, Kmetova A, Hajek P. Do e-cigarettes have the potential to compete with conventional cigarettes?: A survey of conventional cigarette smokers' experiences with e-cigarettes. Chest. 2013;144(5):1609-14, https://doi.org/10.1378/chest.12-2842.

55. Pénzes M, Foley KL, Balázs P, Urbán R. Intention to experiment with e-cigarettes in a cross-sectional survey of undergraduate university students in Hungary. Subst Use Misuse. 2016;9:1-10, https://doi.org/10.3109/10826084.2016.1160116.

56. Rahman MA, Wilson A, Worrall-Carter L. Electronic cigarettes: Patterns of use, health effects, use in smoking cessation and regulatory issues. Tob Induc Dis. 2014;12:21, https:// doi.org/10.1186/1617-9625-12-21.

57. Brown J, West R, Beard E, Michie S, Shahab L, McNeill A. Prevalence and characteristics of e-cigarette users in Great Britain: Findings from a general population survey of smokers. Addict Behav. 2014;39(6):1120-5, https://doi. org/10.1016/j.addbeh.2014.03.009. 
58. Dautzenberg B, Berlin I, Tanguy ML, Rieu N, Birkui P. Factors associated with experimentation of electronic cigarettes among Parisian teenagers in 2013. Tob Induc Dis. 2015;13:40, https://doi.org/10.1186/s12971-015-0065-4.

59. Syamlal G, Jamal A, King BA, Mazurek JM. Electronic cigarette use among working adults - United States, 2014. MMWR Morb Mortal Wkly Rep. 2016;65(22):557-61, https://doi.org/10.15585/mmwr.mm6522a1.

60. Bullen C, Howe C, Laugesen M, McRobbie H, Parag V, Williman J, et al. Electronic cigarettes for smoking cessation: A randomised controlled trial. Lancet. 2013;382(9905): 1629-37, https://doi.org/10.1016/S0140-6736(13)61842-5.

61. Caponnetto P, Campagna D, Cibella F, Morjaria JB, Caruso $\mathrm{M}$, Russo $\mathrm{C}$, et al. EffiCiency and safety of an eLectronic cigAreTte (ECLAT) as tobacco cigarettes substitute:
A prospective 12-month randomized control design study. PLoS One. 2013;8(6):e66317, https://doi.org/10.1371/journal.pone.0066317.

62. Jorenby DE, Leischow SJ, Nides MA, Rennard SI, Johnston JA, Hughes AR, et al. A controlled trial of sustainedrelease bupropion, a nicotine patch, or both for smoking cessation. N Engl J Med. 1999;340(9):685-91, https://doi. org/10.1056/NEJM199903043400903.

63. Nides M, Glover ED, Reus VI, Christen AG, Make BJ, Billing $\mathrm{CB}$, et al. Varenicline versus bupropion SR or placebo for smoking cessation: A pooled analysis. Am J Health Behav. 2008;32:664-75, https://doi.org/10.5555/ajhb.2008.32.6.664.

64. Neuberger M. The electronic cigarette: A wolf in sheep's clothing. Wien Klin Wochenschr. 2015;127(9-10):385-7, https://doi.org/10.1007/s00508-015-0753-3.

This work is available in Open Access model and licensed under a Creative Commons Attribution-NonCommercial 3.0 Poland License - http://creativecommons.org/ licenses/by-nc/3.0/pl/deed.en. 